\title{
Firçasız DA motorunun hız kontrolünde PI katsayılarının Pareto tabanlı çok amaçlı optimizasyonu
}

\author{
Haris CALGAN ${ }^{1, *}, \operatorname{Ramazan~YAMAN}^{2}$, Erdem ILTEN $^{1}$, Metin DEMIRTAŞ $^{1}$ \\ ${ }^{1}$ Balıkesir Üniversitesi Mühendislik Fakültesi Elektrik-Elektronik Mühendisliği Bölümü, Balıkesir. \\ ${ }^{2}$ Istanbul Gelişim Üniversitesi Mühendislik ve Mimarlık Fakültesi Endüstri Mühendisliği Bölümü, \\ İstanbul.
}

Geliş Tarihi (Recived Date): 06.01.2018

Kabul Tarihi (Accepted Date): 14.07.2018

\section{Özet}

Bu makale PI kontrolör katsayllarının (Oransal kazanç $K_{p}$ and Integral kazanç $K_{i}$ ) optimum değerlerini bulmak için Elman Yapay Sinir A ğları (EYSA) modeli kullanılan Pareto tabanlı çok amaçlı optimizasyonu ve Yanıt Yüzey Yöntemi'nin (YYY) karşılaştırılmasını sunmaktadır. Amaç fonksiyonu olarak oturma süresi $\left(T_{s}\right)$ ve maksimum aşma $\left(M_{o}\right)$ seçilmiştir. Çalışmanın amacı, PI kontrolör parametre katsayıları olan $K_{p}$ ve $K_{i}$ 'nin optimum değerlerinin bulunmasıdır. İlk olarak, Minitab programı kullanılarak deney tasarımı gerçekleştirilmiştir. Daha sonra fırçasız doğru akım motoru hiz kontrol sisteminin matematiksel modelinin oluşturulması için YYY ve EYSA modeli ayrı ayrı elde edilmiştir. Son olarak da, optimizasyon işlemi her iki yöntem ile ayrı ayrı gerçekleştirilmiştir. Optimizasyon işlemleri sonucunda, katsayıların optimum değerleri ve Pareto ĕgrisi elde edilmiştir. Elde edilen optimum değerler, sistemde kontrolör içerisine yazılarak firçasız DA motorun gerçek zamanlı çıkışları elde edilmiştir. Sonuçlar karşılaştırıldığında, Pareto tabanlı EYSA yönteminde daha iyi performans sağlandı̆̆g görülmüşsür.

Anahtar Kelimeler: Fırçasız DA motor, YYY, EYSA, Pareto ĕgrisi, çok amaçlı optimizasyon.

\footnotetext{
*Haris CALGAN, haris.calgan@balikesir.edu.tr, http://orcid.org/0000-0002-9106-8144

Ramazan YAMAN, ryaman@gelisim.edu.tr, https://orcid.org/0000-0002-4115-1417

Erdem ILTEN, erdemilten@balikesir.edu.tr, https://orcid.org/0000-0002-9608-2148

Metin DEMIRTAŞ, mdtas@balikesir.edu.tr, https://orcid.org/0000-0003-2622-5286
} 


\title{
Pareto-based multi-objective optimization of PI coefficients for speed control of brushless DC motor
}

\begin{abstract}
This paper present comparison for finding optimum values of PI controller coefficients (Proportional gain $K_{p}$ and Integral gain $K_{i}$ ) by using Elman Neural Network (ENN) model with Pareto based multi-objective optimization method and Response Surface Method (RSM). Objective functions are chosen as settling time $\left(T_{s}\right)$ and maximum overshoot $\left(M_{o}\right)$. The aim of the study is to optimize tuning parameters of PI controller $K_{p}$ and $K_{i}$. Firstly, experimental design has been carried out by using Minitab program. Then, RSM and ENN model have been obtained separately to construct the mathematical model of the brushless DC (BLDC) motor speed control system. Finally, optimization process has been carried out with both methods. Optimum values of coefficients and Pareto front have been obtained after optimization process. The real time outputs of the BLDC motor are obtained by using the obtained optimal values of the coefficients inside of the controller in the system. When compared the results, the better performance is provided by the Pareto based-ENN method.
\end{abstract}

Keywords: Brushless DC motor, RSM, ENN, Pareto front, multi-objective optimization.

\section{Giriş}

Kalıcı mıknatıslı fırçasız DA motorlarının küçük ve hafif yapıda, düşük maliyetli ve basit mekanik yapıda olması, kolay kurulumu ve yüksek verimlilikte çalışması en büyük avantajlarından birisidir. Bu yüzden endüstrideki uygulamalarda giderek artan bir kullanım alanı mevcuttur. Bu motorların endüstri uygulamalarında performansının artırımı için hız kontrol sistemine sahip olması önemli bir etkendir [1].

Oransal-İntegral (PI) kontrolörler basit yapılarından dolayı, endüstride en çok kullanılan kontrol algoritması olma özelliğine sahiptir. Basit yapısına rağmen, bu kontrolörün tasarımı için kullanılan genel bir yöntem yoktur. Kullanılan sürücüdeki makinelerin doğrusal olmayan davranışları, güç dönüştürücüleri vb. ekipmanlar PI kontrolörün karmaşık bir problem haline gelmesini sağlamakta ve ayarlanmasını zorlaştırmaktadır. $\mathrm{Bu}$ yüzden bu tip kontrolörlerin ayarlanması için literatürde birçok yöntem geliştirilmiştir. PI kontrolörün ampirik olarak ayarlanması için genellikle Ziegler\&Nichols yöntemi kullanılmaktadır [2]. Yöntemin basit olması önemli bir avantaj olmasına karşın, her sistem için uygulanamaması ise bir dezavantajdır. Analitik yöntemlerin yanında çeşitli sezgisel algoritmalar kullanılarak da kontrolör katsayılarının optimize edildiği literatürde görülmektedir. Çoban vd. çok amaçlı arı algoritmasını kullanarak kapalı çevrim PID kontrolörün katsayılarının Pareto setine göre ayarlandığ akıllı bir sistem geliştirmişlerdir. Ziegler-Nichols yöntemiyle karşılaştırıldığında bu yöntem daha iyi performans göstermiştir [3]. Erkol, çalışmasında ters sarkaç sisteminin kontrolünde PID kontrolör kullanmış ve kontrolör katsayılarını yapay arı kolonisi algoritması ile optimize etmiştir [4]. Köse vd. enerjinin verimli iletilmesi amacıyla kullanılan Buck dönüştürücüsünün çıkış büyüklügünü PI ile kontrol etmişlerdir. Kontrolör katsayılarını Karınca Kolonisi algoritmasıyla optimize etmişlerdir. Yaptıkları simülasyon çalışmalarına bakıldığında kontrolör performansının iyi olduğu 
görülmektedir [5]. Altun vd. doğru akım motorunun hız kontrolünde klasik PID ve Parçacık Sürü Optimizasyonu (PSO) tabanlı PID kontrolörün performanslarını karşılaştırmışlardır. PSO tabanlı PID’nin referans değerini daha hızlı yakaladığı görülmüştür [6].

Kontrolör katsayılarının ayarlanması için uygun bir sistem modelinin olması gerekmektedir. Sistemdeki bazı parametrelerin göz ardı edilmesi sebebiyle birçok uygulamada matematiksel model fiziksel sistemi tam olarak yansitamamaktadir. Bu yüzden kontrolör katsayıları tam olarak ayarlanamamaktadır. Bilgisayar tabanlı akıllı sistemler kullanılarak bu sorun aşılmaya çalışılmaktadır. YYY [7], YSA ve bulanık mantık [8] gibi yöntemler doğrusal olmayan sistemleri, parametre göz ardı edilmesine veya herhangi bir tahmine gerek kalmadan sistemi gerçeğe yakın bir doğrulukla modelleyebilmektedirler.

Akıllı sistemlerden biri olan YSA; kontrol, hata bulma, dijital sinyal işleme gibi birçok alanda başarılı bir şekilde kullanılmaktadır [9]. Doğrusal olmayan sistemlerin modellenmesinde ve simülasyonunda da başarılı sonuçlar vermektedir. YYY ise sistemin modellenmesi esnasında az sayıda deney yapılmasını taahhüt etmektedir ve böylece zamandan, masraftan kaçınıldığını vurgulamaktadır [10]. Farklı alanlarda her iki yöntemin karşılaştırıldığı çeşitli çalışmalar mevcuttur. Biyokimya alanında [11], [12], yapısal analiz çalışmalarında [13], gıda biliminde [14] yapılan çalışmalarda YSA'nın daha iyi sonuçlar verdiği görülmektedir.

PI kontrolörün bu çalışmada maksimum aşma $\left(M_{o}\right)$ ve oturma süresi $\left(T_{s}\right)$ olmak üzere iki adet amaç fonksiyonu mevcuttur. Birden fazla amaç fonksiyonuna sahip problemler çok amaçlı optimizasyon problemi olarak tanımlanmaktadır [15]. Bu tip problemlerin çözümünde Pareto tabanlı çok amaçlı optimizasyon yaklaşımı kullanılmaktadır [16]. Bu yaklaşımda Pareto baskınlık kavramına göre çözümler arasındaki korelasyon ve böylelikle Pareto optimum çözüm seti oluşturulmaktadır. Literatürdeki Pareto tabanlı çok amaçlı optimizasyon yönteminin kullanıldığı çalışmalara bakıldığında başarılı sonuçların alındığı görülmektedir. Sharafi vd. birden fazla generatör ve depolama birimine sahip hibrit enerji sistemlerinin optimal tasarımı için yeni bir yaklaşım kullanmıştır. Çalışmalarında toplam maliyeti, karşılanamayan yükü ve emisyonu amaç fonksiyonları olarak ele alarak, enerji üretim birimlerinin optimum kapasitelerini araştırmışlardır [17]. Subasi vd. çalışmalarında sistemi YYY ile modelleyerek Pareto tabanlı çok amaçlı optimizasyon gerçekleştirmişlerdir. Tasarım parametrelerinin optimum değerlerine ulaşmışlardır [18]. Wei vd. Pareto tabanlı çok amaçlı genetik algoritma kullanarak saç metalin şekillendirme işlemini optimize etmişlerdir [19]. Diğer bir çalışmada ise Madavan, Pareto tabanlı yaklaşımı kullanarak Diferansiyel Gelişim Algoritmasını kullanmıştır. Test problemlerine uygulayarak iyi sonuçlar almıştır [20].

Bu çalışmada, fırçasız DA motorunun hız kontrolör katsayılarının optimizasyonu için iki farklı yöntemden alınan sonuçlar karşılaştırılmıştır. Kullanılan DA sistemi tanıtılmış ve hız kontrol uygulaması sunulmuştur. YY yönteminden bahsedilmiş ve deney tasarımı gerçekleştirilmiştir. Elde edilen deneysel sonuçlar ile YY modeli, model üzerinden de kontrolör katsayılarının optimum değerleri bulunmuştur. Aynı deneysel veriler kullanılarak Elman YSA ile sistem tekrar modellenmiştir. Bu model üzerinden çok amaçlı optimizasyon işlemi gerçekleştirilerek katsayılara bağlı optimum noktalardan oluşan Pareto eğrisi elde edilmiştir. Son bölümde, YYY ve Pareto eğrisinden elde edilen katsayılar gerçek sistemde kullanılarak DA motoru sürülmüş ve hız tepkileri 
kaydedilmiştir. $\mathrm{Bu}$ amaçla makale içeriğinin ikinci bölümünde materyal ve yöntem açıklanmış, üçüncü bölümde sonuçlar ve bulgular tartışılmış, dördüncü bölümde ise elde edilen sonuçlar ve karşılaştırmaların neticesi kısaca yorumlanmıştır.

\section{Materyal ve yöntem}

\subsection{PI kontrolör}

PI kontrolörün zamana bağlı denklemi şöyle ifade edilebilir

$\mathrm{u}(\mathrm{t})=K_{p} \mathrm{e}(\mathrm{t})+K_{i} \int \mathrm{e}(\mathrm{t}) \mathrm{dt}$

Eşitlik (1)'deki e(t) hata fonksiyonudur, $K_{p}$ ve $K_{i}$ sırasıyla oransal ve integral kontrol katsayılarıdır. PI kontrolörün kullanıldığı bir sistemin blok şeması Şekil 1'de verilmektedir.

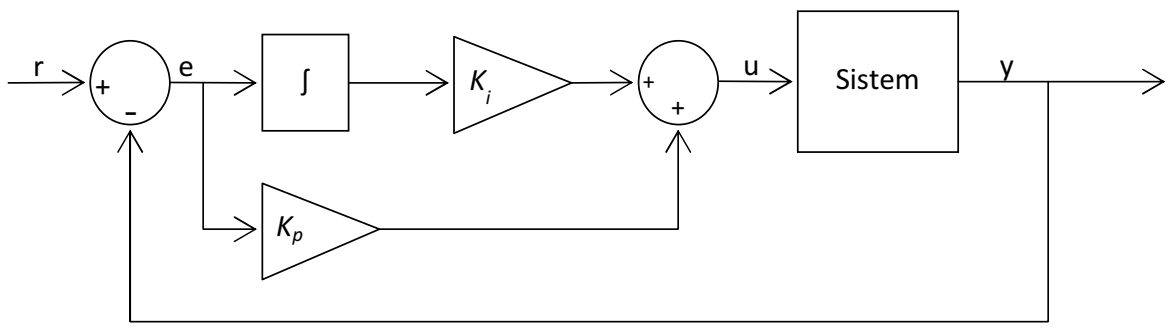

Şekil 1. PI kontrolör blok şeması.

Şekil 1'de r referans değeri, e hata değerini, u kontrol işaretini y ise sistemin çıktısını göstermektedir.

\subsection{DSP tabanlı firçasız DA motorun hız kontrolï uygulaması}

Fırçasız DA motorların fırçalı motorlara göre yüksek verimli olması, moment-hız ilişkisinin doğrusal olması, daha küçük boyutlarda olup daha yüksek moment üretebilmesi, fırça ve kollektör barındırmaması sebebiyle arıza yapma ihtimalinin düşük olması gibi avantajlarından dolayı son yıllarda yapılan uygulamalarda daha fazla tercih edilmeye başlanmıştır. $\mathrm{Bu}$ avantajlarının yanında rotor mıknatıslarının maliyeti artırması, fırça ve kollektör bulunmadığ 1 için komütasyon işleminin harici bir inverter ve hall etkili sensörler kullanılarak yapılması gibi dezavantajlarının bulunması, fırçasız DA motorların tüm motor uygulamaları alanına hakim olmasını engellemektedir.

Bu çalışmada MCK243 fırçasız DA motor deney kiti kullanılmıştır. MCK243 kiti bir adet fırçasız DA motor, motor sürücü devresi ve TMS320F243 dijital işaret işleyici (Digital Signal Processor, DSP) entegresi barındırmaktadır. Ayrıca bilgisayar üzerinden PI kontrolör katsayıları, örnekleme periyodu, referans hız bilgisinin girilebildiği ve yapılan deneyin sonuçlarının (ölçülen hız bilgisi, $\dot{\mathrm{I}}_{\mathrm{d}}$ ve $\dot{\mathrm{I}}_{\mathrm{q}}$ akım bileşenleri) grafik olarak çizdirilebildiği bir demo yazılımı da mevcuttur. Şekil 2'de referans hız ve örnekleme periyodu ayarlama ekranı, Şekil 3'te ise PI kontrolör katsayılarının girildiği ekran görülmektedir. 


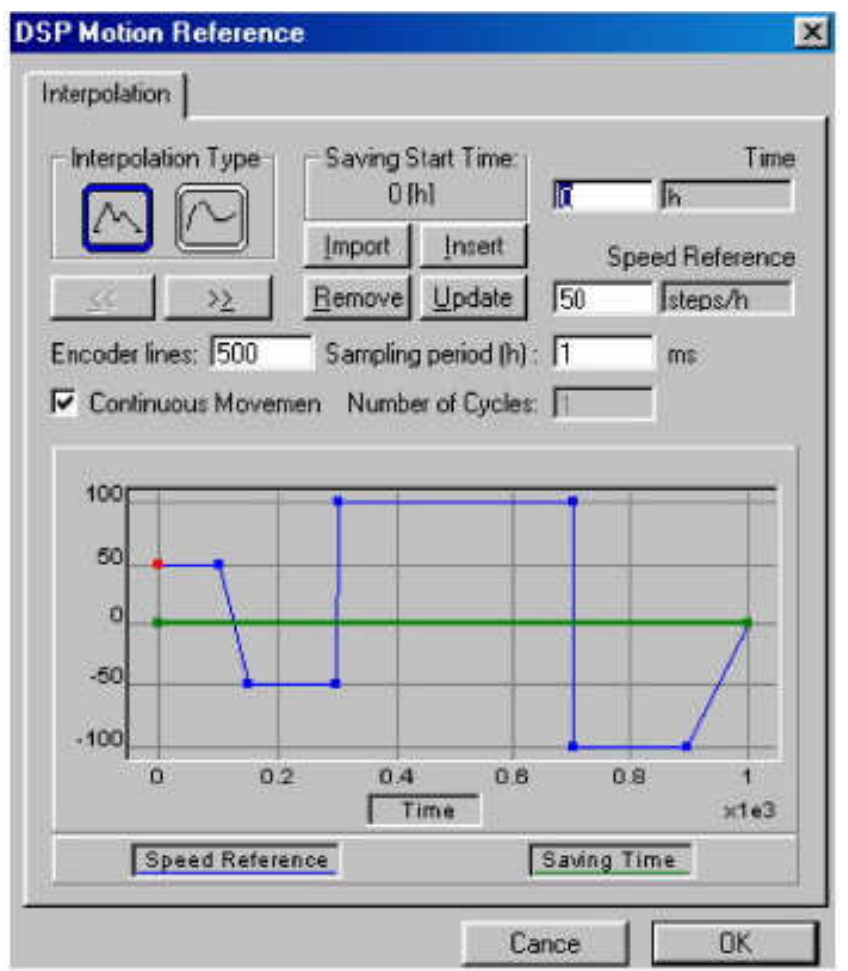

Şekil 2. Referans hız ve örnekleme periyodunun ayarlanması.

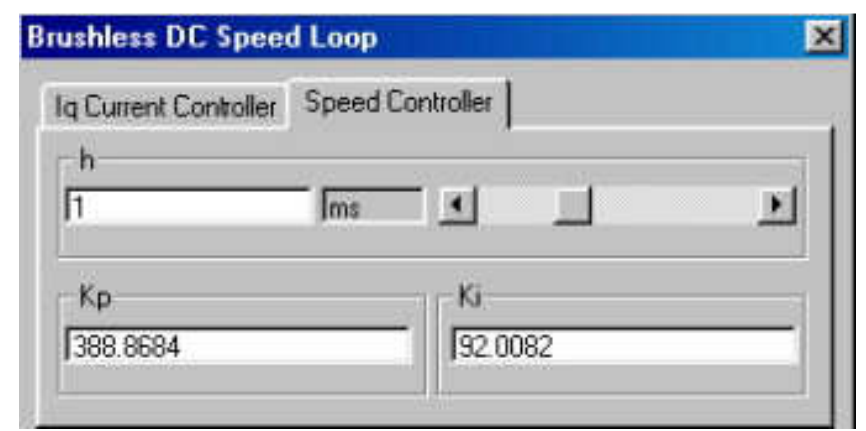

Şekil 3. PI kontrolör katsayılarının ayarlanması.

MCK243 kiti MC-Bus konnektörü üzerinden bilgisayara bağlanmaktadır. Kitin üzerinde bulunan PM-50 kartı ile MC-Bus konnektörü arasındaki bağlantılar Şekil 4'te verilen PM-50 kartının blok şemasında görülmektedir. 


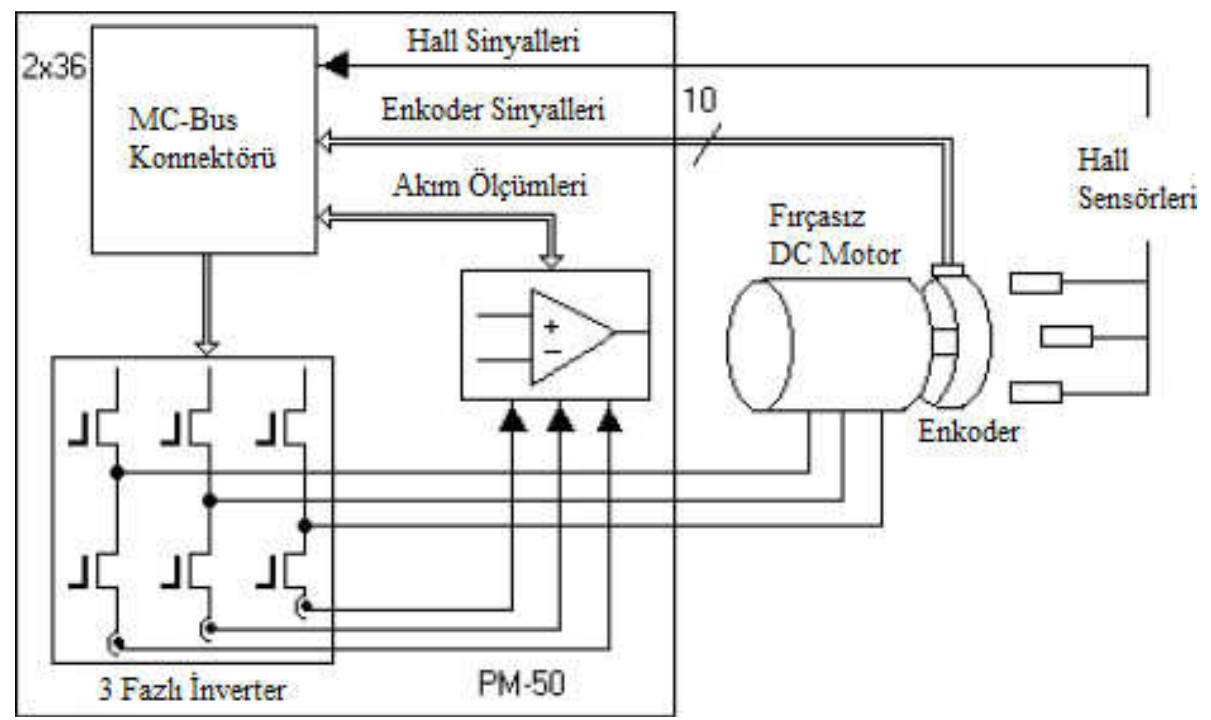

Şekil 4. PM-50 kartının blok şeması.

PM-50 kartı üzerinde 1.7 Amper ve 36 Volt girişli üç fazlı inverter de bulunmaktadır. Fırçasız motor üzerindeki enkoder ve hall sensörlerinden gelen bilgiler PM-50 kartı üzerinden MC-Bus konnektörüne bağlanmaktadır.

Fırçasız DA motorun rotor konum bilgisi ve akım bilgileri sırasıyla enkoder ve hall etkili sensörleri ile okunmaktadır. Enkoder bir tam turunda 500 darbe üretebilmektedir ve hall sensörleriyle birlikte motorun mili üzerine monte edilmiştir. Şekil 5 'te deney düzeneğinin görüntüsü verilmektedir.

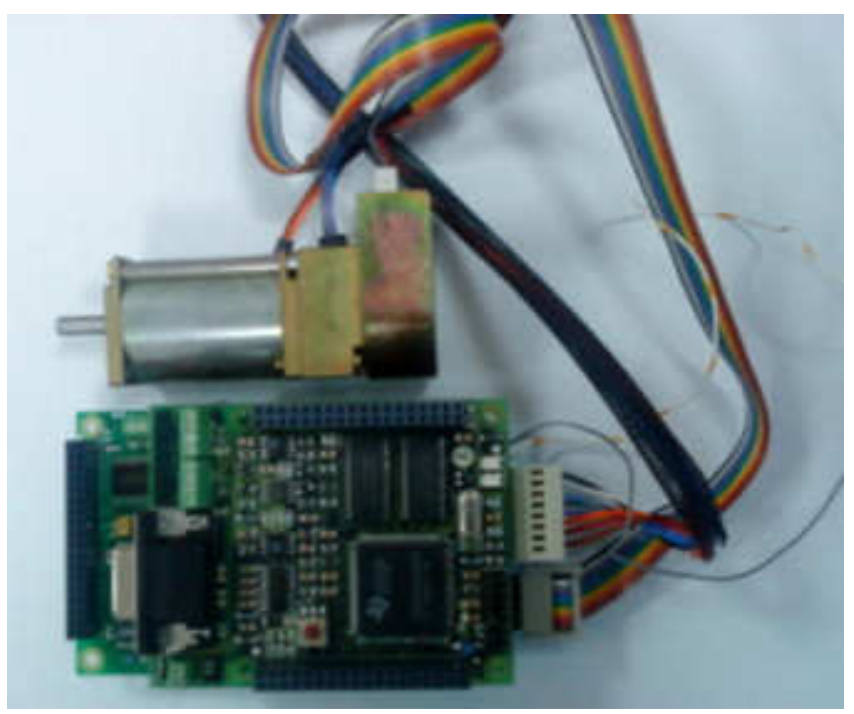

Şekil 5. Deney düzeneğinin görüntüsü.

\subsection{Yanıt yüzey yöntemi ile kontrolör katsayıların optimizasyonu}

YYY proseslerin geliştirilmesi ve optimizasyonu için gerekli istatistiksel ve matematiksel tekniklerin birlikte kullanıldığı bir yöntemdir. Endüstride, süreçlerin veya ürünlerin performansını etkileyen giriş değişkenlerini karakterize etmek ve incelemek için kullanılmaktadır. YYY kullanılarak gerçekleştirilen optimizasyonlarda deneylerin sınırlı bir sayıya düşürülmesi, bu yöntemin daha ucuz olduğunu ve zamandan tasarruf 
sağladığını göstermektedir. Sistemin önemli faktörleri belirlendikten sonra model oluşturulabilmesi için kullanılmaktadır. Optimizasyon çalışması için Fırçasız DA motorun PI hız kontrolörünün girişleri $\left(K_{p}\right.$ ve $\left.K_{i}\right)$ bağımsız değişken faktörler olarak seçilmiștir. YY tipi olarak ise yüzey merkezli kompozit tasarımı (Face Central Composite Design) seçilmiştir. Bu tasarım ile matematiksel modellerin yetersiz kaldığı durumlarda ikinci dereceden denklemlerin oluşturulması sağlanır [21]. Böylelikle, optimum koşulların bulunması için gereken modele ikinci dereceden terimler dahil edilmiştir. Modele, yüksek dereceden terimlerin dahil edilmemesinin en büyük nedeni ise katsayıların hesaplanmasının zorlaşmasıdır. İkinci dereceden merkez kompozit tasarımlı YY modeli Eşitlik 2'deki formül ile bulunmaktadır [13].

$\widehat{G}(X)=a+\sum_{i=1}^{n} b_{i} x_{i}+\sum_{i=1}^{n} c_{i} x_{i}^{2}$

Buradaki $\hat{G}(X)$, sistemin çıkışlarını gösteren ikinci dereceden polinomu, $a, b_{i}, c_{i}$ terimleri ise polinomun hesaplanması gereken katsayılarını göstermektedir. Toplam deney sayısı ise Eşitlik 3'teki formül ile bulunur [22].

$N=2^{k}+2 k+n c$

Eşitlikteki $k$ toplam faktör sayısını, $n c$ merkez noktasının tekrar sayısını, $N$ ise toplam yapılacak deney sayısını göstermektedir. Yüzey merkezli seçilen sistemde eksenlerin dışına çıkılmadan kompozitin yüzeylerindeki noktalar seçilmektedir. Bu çalışmada, kontrolör parametre katsayılarının belirlenmesi için katsayıların minimum ve maksimum değerleri Minitab programına girilerek, deney sayısı ve deneyde kullanılacak katsayılar Tablo 1'de gösterildiği gibi elde edilir. Elde edilen tablodaki deneyler yapılarak, sistemin oturma süresi ve maksimum aşım değerleri $\left(M_{o}\right.$ ve $\left.T_{s}\right)$ için YY modeli elde edilir.

Tablo 1. Deney tasarımı ve deneysel sonuçları.

\begin{tabular}{|c|c|c|c|c|}
\hline Deney No & $K_{p}$ & $K_{i}$ & $T_{s}(\mathrm{~ms})$ & $M_{o}(\mathrm{~d} / \mathrm{d})$ \\
\hline 1 & 550 & 45 & 60,00 & 3,00 \\
\hline 2 & 750 & 45 & 75,00 & 0,00 \\
\hline 3 & 550 & 75 & 52,00 & 7,00 \\
\hline 4 & 750 & 75 & 55,00 & 2,00 \\
\hline 5 & 550 & 60 & 64,50 & 4,50 \\
\hline 6 & 750 & 60 & 51,75 & 0,75 \\
\hline 7 & 650 & 45 & 55,00 & 1,00 \\
\hline 8 & 650 & 75 & 52,50 & 3,25 \\
\hline 9 & 650 & 60 & 50,00 & 2,00 \\
\hline 10 & 650 & 60 & 49,50 & 1,50 \\
\hline 11 & 650 & 60 & 50,25 & 1,50 \\
\hline 12 & 650 & 60 & 48,75 & 1,90 \\
\hline 13 & 650 & 60 & 50,00 & 1,50 \\
\hline
\end{tabular}

Minitab programı kullanılarak elde edilen YYY modeline göre ise amaçların ayrı ayrı polinomları elde edilmiştir. Elde edilen bu denklemler Eşitlik (4) ve (5)'te verilmiştir. 


$$
\begin{aligned}
& M_{o}=41,00-0,1180 K_{p}+0,0890 K_{i}+0,000091 K_{p} * K_{p}+0,001828 K_{i}^{*} K_{i}-0,000333 K_{p} * K_{i} \\
& T_{s}=360-0,861 K_{p}-0,77 K_{i}+0,000762 K_{p} * K_{p}+0,0144 K_{i} * K_{i}-0,00200 K_{p} * K_{i}
\end{aligned}
$$

Tablo 1'de verilen $\mathrm{K}_{\mathrm{p}}$ ve $\mathrm{K}_{\mathrm{i}}$ katsayılarının minimum ve maksimum değerleri arasındaki veriler Minitab programı üzerinden Eșitlik 4 ve 5'te verilen YY modeline artımsal olarak uygulanmaktadır. Model sonuçları kullanılarak Şekil 6'daki grafik elde edilmektedir. Sistemin çıkışlarının $\left(M_{o}\right.$ ve $\left.T_{s}\right)$ her ikisinin de optimum olması gerektiği düşünülerek, grafik üzerinde oturma süresini $\left(T_{s}\right)$ ve maksimum aşma $\left(M_{o}\right)$ değeri elde edilmektedir. Grafik üzerinde gösterilen $M_{o}$ ve $T_{s}$ eğrilerinin dikey olarak çizilen $K_{p}$ ve $K_{i}$ eğrilerini kestiği noktalar optimal değerler olarak bulunmuştur. Grafikteki d değeri ise sistemin istenen değere yaklaşma oranını gösterir ve d'nin maksimum değeri 1'dir. $\mathrm{Bu}$ grafiklere göre $K_{p}{ }^{\prime}$ nin optimum değeri $685,3535, K_{i}$, nin optimum değeri ise 61,6667 olarak bulunmuştur. Bulunan katsayıların kullanılması durumunda oturma süresinin $50,54 \mathrm{~ms}$, aşmanın ise 1,2494 d/d olduğu görülmektedir. Ayrıca YY modelinin regresyon değeri $\left(\mathrm{R}_{\text {sq }}\right) \% 98,85$ çıkmıştır. Bu da elde edilen matematiksel modelin sistemi doğru bir şekilde yansıttı̆̆ını göstermektedir.

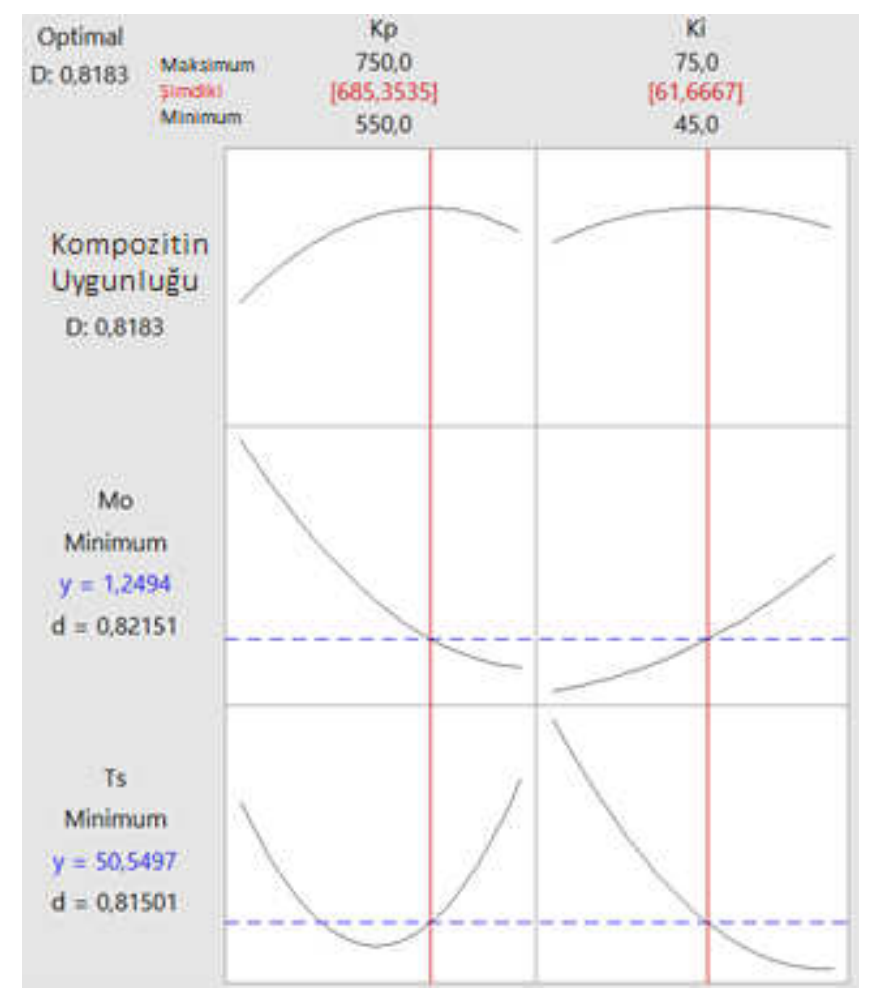

Şekil 6. YYY optimizasyon sonuçları.

\subsection{Elman yapay sinir ağları ile kontrolör katsayılarının optimizasyonu}

\subsubsection{EYSA modelinin elde edilmesi}

Geri beslemeli yapay sinir ağlarından birisi olan EYSA'nın genel yapısı Şekil 7'de gösterilmiştir. Bu sistemde gizli katmanın çıkışı bağlam noktalarına alınarak bir sonraki döngüde giriş olarak kullanılmaktadır. Böylelikle EYSA, klasik yapay sinir ağlarına göre daha dinamik bir hale gelmektedir [23]. Bu özelliğinden dolayı EYSA, doğrusal olmayan sistemlerin modellenmesinde ve kontrolünde literatürde çokça 
kullanılmaktadır [24]. Hit ve Trail, Ziegler-Nichols [25] gibi klasik yöntemlerin aksine EYSA, doğrusal olmayan kontrol sistemlerini, kontrolör katsayılarına bağlı çok amaçlı optimizasyon problemi olarak modelleyebilmektedir.

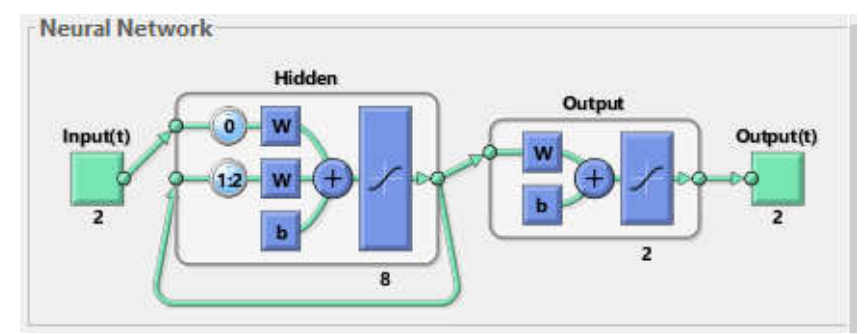

Şekil 7. EYSA genel yapısı.

Bu bölümde, Tablo 1'de verilen deneyler ve sonuçları kullanılarak ESYA modelinin elde edilmesi amaçlanmıştır. ESYA'nın girişi olarak kontrolör katsayıları $K_{p}$ ve $K_{i}$ alınmıştır. Çıkış değişkenleri olarak $M_{o}$ ve $T_{s}$ alınmıştır. 3 katmandan oluşan ağın gizli katmanında 8 adet nöron bulunmaktadır. Gizli katmanın ve çıkış katmanının aktivasyon fonksiyonu olarak tanjant sigmoid kullanılmıştır. Tablo 1'deki deneysel verilere göre Levenberg-Marquardt yöntemiyle eğitim gerçekleşmiştir. Eğitim sonunda ortalama karesel hata 0.064346 olarak bulunmuştur. Eğitim sonucu elde edilen ortalama karesel hata grafiği Şekil 8'de görünmektedir. Elde edilen EYSA modeli çok amaçlı optimizasyon için kullanılacaktır.

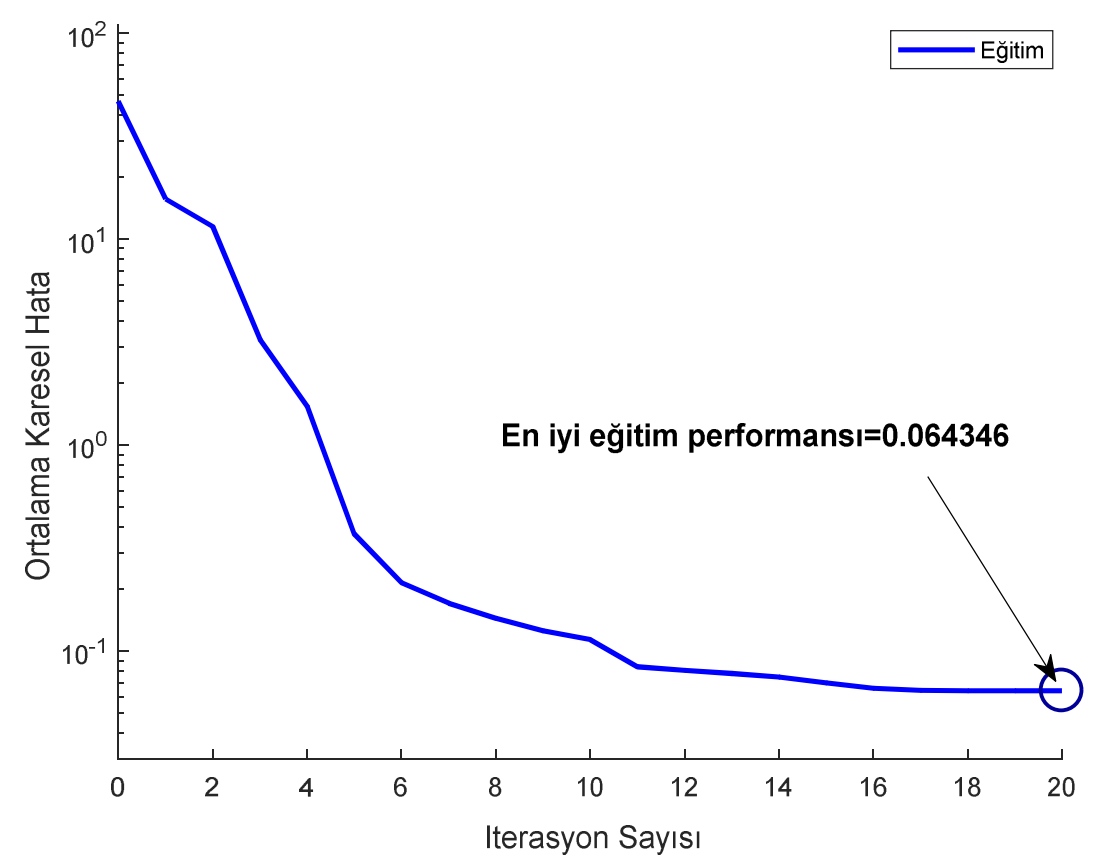

Şekil 8. ESYA eğitimi performans grafiğii.

Şekil 8'de görüldüğü gibi 20 iterasyon sonucu eğitim sonlandırılmıştır. Eğitim sonucu ortalama karesel hata değeri en düşük seviyeye düşmüştür. Bu çalışmada EYSA ile YYY karşılaştırılması yapılmıştır. YYY'nin diğer yöntemlere göre avantajlarından birisi deney sayısının azaltılmasıdır. Bu karşılaştırmanın eşit deney sayısında yapılabilmesi için her iki yöntemin eğitiminde aynı eğitim seti kullanılmıştır. EYSA ile 
YYY sonuçlarını karşılaştırmak ve EYSA modelinin doğruluğunun testi için ayrıca deney yapılmamıştır. Yüzey merkezli kompozit tasarımının oluşturulabilmesi için gerekli olan eğitim seti 13 satırdan oluştuğu için yapay sinir ağı da aynı sayıda eğitim seti ile eğitilmiştir. YY modelinin başarısı regresyon değerine bakılarak görülmektedir.

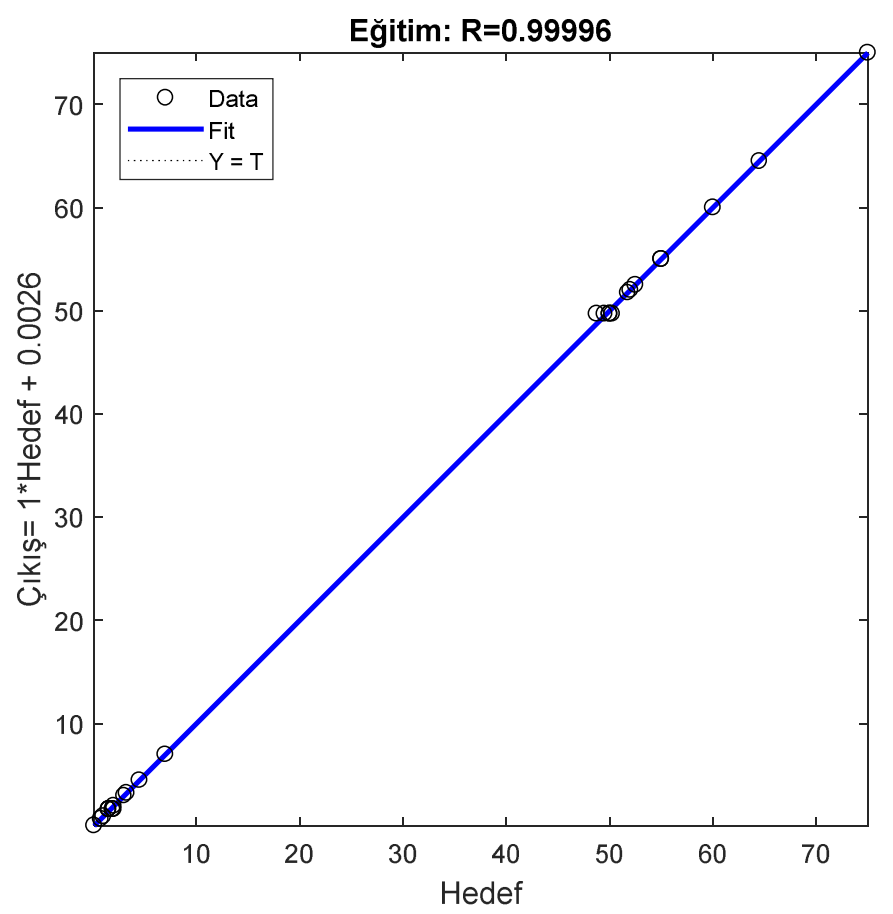

Şekil 9. ESYA regresyon grafiği.

Çalışmada kullanılan EYSA'nın YYY ile eşit şartlarda karşılaștırılması ve EYSA modelin testi için gerekli deneyler gerçekleştirilmeden, EYSA'nın eğitimi sonucu elde elde edilen regresyon değeri, EYSA'nın başarı ölçütü olarak değerlendirilmiştir. Şekil 9'da verilen regresyon grafiğine bakıldığında elde edilen EYSA regresyon değeri $\% 99,99$ olarak elde edilmiştir. Bu değer modelin doğru oluşturulduğunu göstermektedir.

\subsubsection{EYSA modelinin çok amaçlı optimizasyonu}

Fırçasız DA motoru PI hız kontrolör katsayılarının düzgün bir şekilde belirlenmesi motorun doğrusal olmayan davranışı sayesinde karmaşık bir problem haline gelmektedir. Kullanılan kontrol sistemlerinde, $M_{o}$ '1n ve $T_{s}^{\prime}$ 'nin mümkün olduğunca düşük seviyelerde olması kontrolör performansının iyi olduğunu göstermektedir [6]. Ancak Pareto optimizasyonunda elde edilen aşım yada oturma süresi kullanılan sisteme göre farklı çözümler sunmaktadır. Bu yüzden, $M_{o}$ ve $T_{s}$ amaç fonksiyonları olarak belirlenmiştir. Tasarlanan optimizasyon problemi Eşitlik (6)' da verilmiştir. 


$$
\begin{cases}\text { Bul } & K_{p}, K_{i} \\ \text { Min } & M_{o}=f_{1}\left\{K_{p}, K_{i}\right\} \\ \text { Min } & T_{s}=f_{2}\left\{K_{p}, K_{i}\right\} \\ \text { Kisitlar }= & \\ & 550 \leq K_{p} \leq 750 \\ & 45 \leq K_{i} \leq 75\end{cases}
$$

Eşitlik (6)' da gösterilen optimizasyon problemi birden fazla amaç fonksiyonu içerdiği için 'Çok amaçlı optimizasyon problemi' olarak tanımlanmaktadır ve bu amaçlar genellikle birbiriyle çelişmektedirler [26]. Bu tip problemlerde hangi çözümün diğer olası çözümlerden daha önce olduğunu belirtmek veya bu çözümleri bir sıralamaya koyma işlemi Pareto Optimal çözümlerini karşımıza çıkarmaktadır [27-28]. Çalışmadaki Pareto eğrisinin elde edilmesine kadar uygulanan adımlar Şekil 10'daki blok diyagramında görülmektedir.

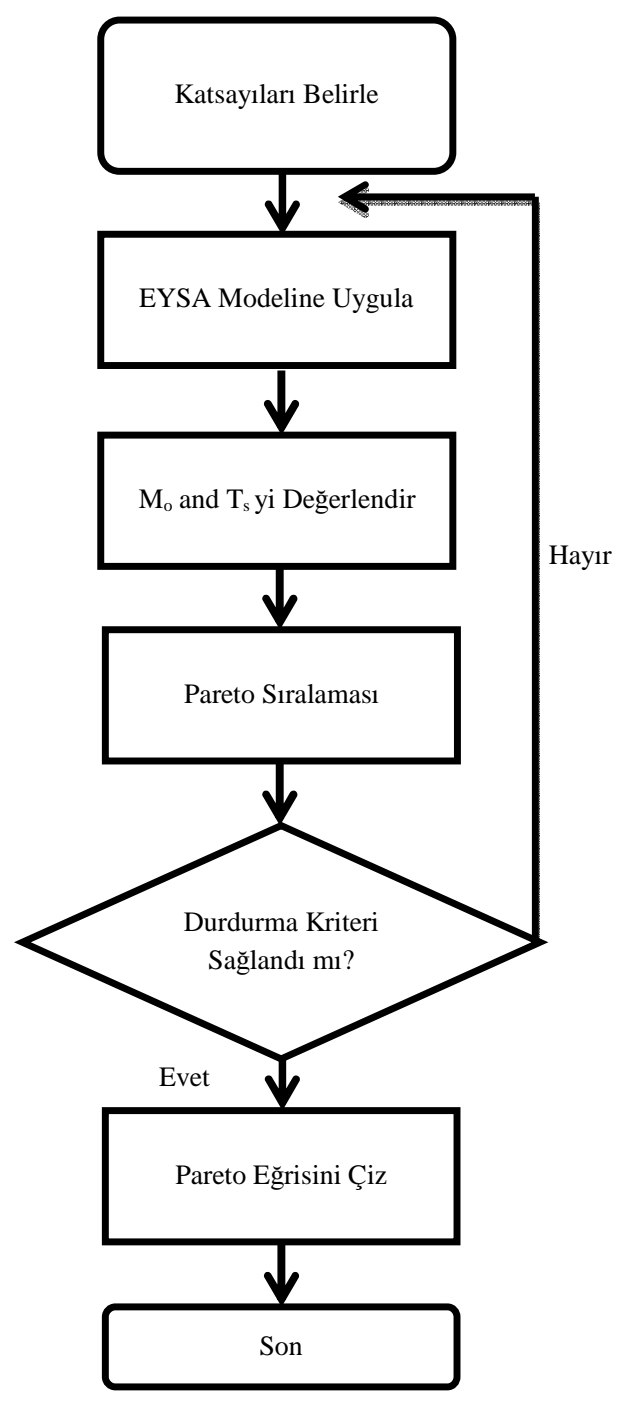

Şekil 10. Çok amaçlı optimizasyon algoritmasının uygulama basamakları. 
Çalışmada doğrusal olmayan Fırçasız DA motorun EYSA modelinin genetik algoritmalar kullanılarak çözülmesi sonucu Pareto eğrisi elde edilmiştir. Kullanılan genetik algoritmanın parametreleri şu şekilde seçilmiştir:

- Popülasyon büyüklügü: 45

- Üreme Katsayısı: 0.8

- Maksimum nesil sayısı: 60

- Çaprazlama oranı: 0.80

- Mutasyon fonksiyonu: Sinırlı

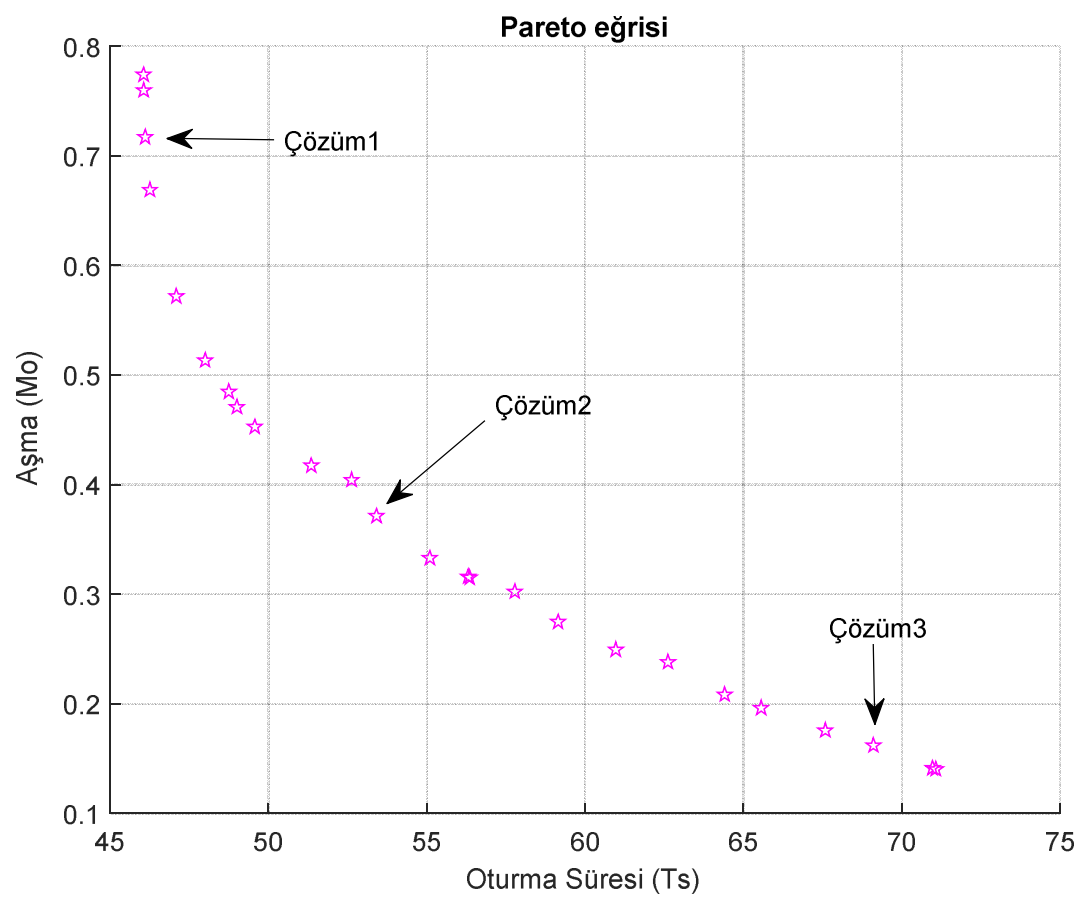

Şekil 11. Pareto eğrisi.

Eşitlik (6)' da gösterilen optimizasyon probleminin Pareto optimum çözümleri Şekil 11 'de görülmektedir. Pareto eğrisi olarak adlandırılan şekilde her bir nokta çok amaçlı optimizasyonun bir optimum çözümüdür ve bu çözümlerin birbiri üzerinde üstünlükleri yoktur. Uzman kişiler tarafından herhangi bir amacın daha üstün olduğu düşünülürse, diğer amaçtan fedakarlık yapılarak Pareto eğrisinden seçim yapılabilir. Şekil 11'de görülen Çözüm1, Çözüm2 ve Çözüm3 noktalarının değerleri Tablo 2'de verilmiştir. Bu tabloya da bakıldığında; Çözüm1'de yüksek aşma değeri, düşük oturma süresi olduğu, Çözüm3'te ise düşük aşma değeri ve yüksek oturma süresi olduğu görülmektedir. Çözüm2 her iki amacın eşit önemde olduğu noktadır.

Tablo 2. Optimum çözüm noktaları.

\begin{tabular}{|c|c|c|c|c|}
\hline Çözüm & $K_{p}$ & $K_{i}$ & $M_{o}(\mathrm{~d} / \mathrm{d})$ & $T_{S}(\mathrm{~ms})$ \\
\hline 1 & 688,7086 & 53,2560 & 0,75 & 46,5 \\
\hline 2 & 727,1380 & 50,7070 & 0,3 & 55 \\
\hline 3 & 739,5725 & 45,3406 & 0,01 & 65 \\
\hline
\end{tabular}




\section{Sonuçlar ve tartışma}

YYY ile bulunan optimum $K_{p}$ ve $K_{i}$ değerleri (685.35 ve 61.66), Firçasız DA motorun hız kontrolör bloğuna girilmiştir. Çalıştırılan sistemin hız tepkisi Şekil 12'de görülmektedir. Buna göre DA motorun $50 \mathrm{~d} / \mathrm{d}$ 'lik referans hız değerine ulaşması için yaklaşık olarak $25 \mathrm{~ms}$ geçmiştir. Motorun hız tepkisinin referans değere oturması için geçen süre $\left(T_{s}\right) 50 \mathrm{~ms}$ olmuş ve maksimum aşma $1 \mathrm{~d} / \mathrm{d}$ olarak kaydedilmiştir.

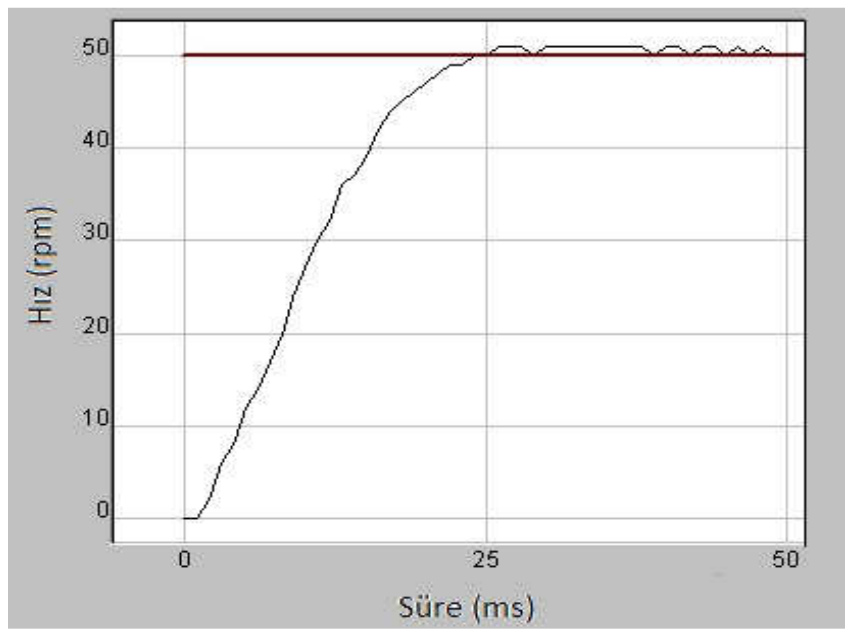

Şekil 12. YYY ile elde edilen katsayıların hız tepkisi.

Pareto eğrisinde ele alınan üç nokta Çözüm1, Çözüm2 ve Çözüm3 olarak adlandırılmıştı. Bu üç çözümde bulunan optimum noktaların (Tablo 2) sirasıyla MCK243 kitinin kontrolör bloğuna girilmesi sonucu Şekil 12 elde edilmiştir. Sistemin hız tepkisinde elde edilen sonuçlar, Tablo 2'deki çok amaçlı optimizasyon sonuçlarıyla örtüşmektedir. Çözüm1 noktasının hız tepkisi olan Şekil 13.a'da Fırçasız DA motorun hızı yaklaşık olarak 25 milisaniyede referans hız değerine ulaşmış ve 46. milisaniyede oturmuştur. Maksimum aşma değeri ise $0,75 \mathrm{rpm}$ olarak görülmektedir. Şekill3.b, Çözüm2'nin hız tepkisini göstermektedir. Bu şekle göre maksimum aşmanın $0,3 \mathrm{~d} / \mathrm{d}$ ve oturma süresinin yaklaşık olarak 55 milisaniye olduğu görülmektedir. Çözüm3 de ise oturma süresinden feragat edilmiştir. Böylelikle aşmanın sıfır olması istenmiştir. Şekil 13.c'de Çözüm3'ün hız tepkisinden göründüğü üzere oturma süresi 60 milisaniyenin üzerindedir ve aşma minimuma indirilmiştir.

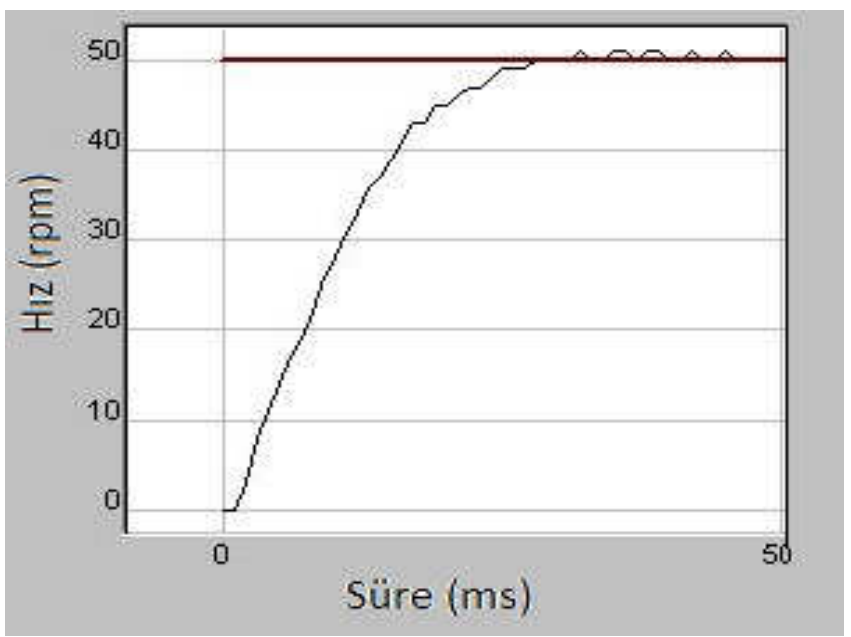

a. Çözüm1 katsayılarının hız tepkisi 


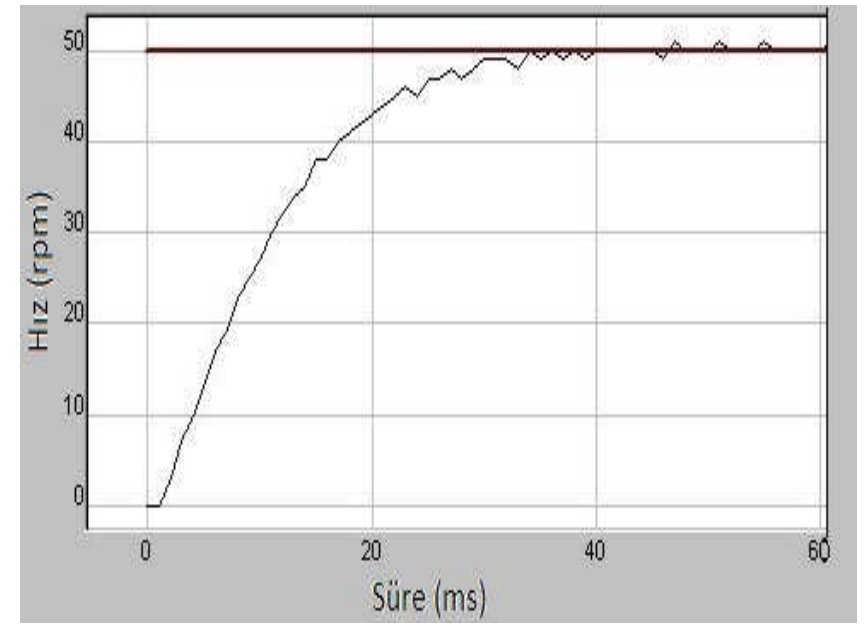

b. Çözüm2 katsayılarının hız tepkisi

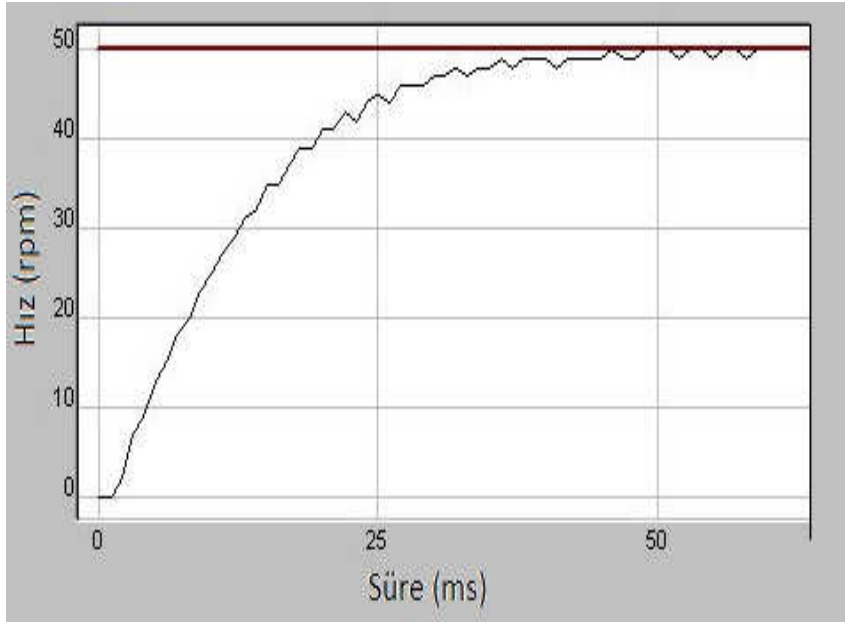

c. Çözüm3 katsayılarının hız tepkisi

Şekil 13. EYSA ve Çok amaçlı optimizasyon ile elde edilen katsayıların hız tepkileri.

Elde edilen sonuçlara göre EYSA'nın çok amaçlı optimizasyonu sonucu elde edilen Pareto eğrisi kullanıcıya birden fazla seçenek sunmuştur. $M_{o}$ değerinin endüstride daha önemli olduğu göz önünde bulundurularak Çözüm1 değerleri ele alındığında ESYA modelinin YYY modelinden daha üstün olduğu görünmektedir. Elde edilen veriler Tablo 3.'te sayısal olarak gösterilmektedir.

Tablo 3. Fırçasız DA motoru hız tepkisi sonuçları

\begin{tabular}{|c|c|c|c|c|}
\hline Yöntem & $K_{p}$ & $K_{i}$ & $M_{o}(\mathrm{~d} / \mathrm{d})$ & $T_{s}(\mathrm{~ms})$ \\
\hline YYY & 685,3535 & 61,6667 & 1,0 & 49 \\
\hline $\begin{array}{c}\text { EYSA Çok } \\
\text { Amaçl1 } \\
\text { Optimizasyon }\end{array}$ & 688,7086 & 53,2560 & 0,75 & 45 \\
\hline
\end{tabular}




\section{Sonuçlar}

Bu çalışmada doğrusal olmayan bir sistem olan Fırçasız DA motorunun PI hız kontrolör katsayılarının iki farklı yöntem ile optimum değerlerinin bulunması ve bu değerlere göre sistemin performansı analiz edilmiştir. YYY modelinin oluşturulabilmesi için deney tasarımı yapılmış ve veri seti oluşturulmuştur. YYY'nin optimizasyonu sonucu elde edilen katsayılar girilerek sistem çalıştırılmıştır. Aynı veri seti EYSA'nın eğitilmesi için de kullanılmıştır. Elde edilen regresyon grafiklerine göre EYSA modelinin daha iyi eğitildiği görülmüştür. EYSA modelinin çok amaçlı optimizasyonu ile Pareto eğrisine ulaşılmıştır. Bu eğriden üç optimum nokta seçilerek sisteme uygulanmıştır. YYY ile bulunan optimum katsayılar ile $M_{o}{ }^{\prime}$ 1n $1 \mathrm{~d} / \mathrm{d}, T_{s}{ }^{\prime}$ nin $49 \mathrm{~ms}$ olduğu; Pareto tabanlı çok amaçlı optimizasyon tekniği kullanılarak bulunan optimum katsayılar ile de $M_{o}$ ' 1 n $0.75 \mathrm{~d} / \mathrm{d}, T_{s}$ 'nin $45 \mathrm{~ms}$ olduğu deneysel olarak elde edilmiştir. Sistemin hız tepkilerine göre Pareto tabanlı optimizasyon yönteminin YYY'e göre daha iyi sonuçlar verdiği görülmektedir. Sonuç olarak YYY'nin deney sayısını az tutarak optimizasyon yapabilme ve zamandan tasarruf sağlama özelliği, ESYA kullanılarak yapılan Pareto tabanlı çok amaçlı optimizasyon tekniğiyle de gerçekleştirilmiştir. Ayrıca YYY'de tek bir sonuç alınabiliyorken, Pareto tabanlı optimizasyon ile kullanıcının isteğine göre sistem farklı optimum noktalarda çalıştırılabilmektedir.

\section{Kaynaklar}

[1] Demirtas, M., Off-line tuning of a PI speed controller for a permanent magnet brushless DC motor using DSP, Energy Conversion Management, 52, 1, 264273, (2011).

[2] Tajjudin, M., Rahiman, M.H.F., Arshad N. M. ve Adnan, R., Robust fractionalorder PI controller with Ziegler-Nichols rules, International Journal of Electrical and Computer Engineering, 7, 7, 1036-1041, (2013).

[3] Çoban, R. ve Erçin, Ö., Multi-objective Bees Algorithm to Optimal Tuning of PID Controller, Cukurova University Journal of the Faculty of Engineering and Architecture, 27, 2, 13-26, (2012).

[4] Erkol, H.O., Ters sarkaç sisteminin yapay arı kolonisi algoritması ile optimizasyonu, Politeknik Dergisi, 20, 4, 863-868, (2017).

[5] Ercan, K., Mühürcü, A., Mühürcü, G., ve Aydoğan, E., Buck Dönüştürücü Çıkış Geriliminin Karınca Koloni Algoritması Kullanılarak PI Tabanlı Optimal Kontrolü, Çukurova Üniversitesi Mühendislik-Mimarlık Fakültesi Dergisi, 32, 4, 153-162, (2017).

[6] Altun, M., Celik, Y., ve Güneş, M., Doğru Akım Motorunun Hız Denetiminde Parçacık Sürü Optimizasyonu Tabanlı PID, Klasik PID ve Bulanık Tipi Denetim Yöntemlerinin Başarımlarının İncelenmesi, Kahramanmaraş Süiçü İmam Üniversitesi Mühendislik Bilimleri Dergisi, 20, 4, 158-167, (2017).

[7] Ilten, E. ve Demirtas, M., Off-Line Tuning of Fractional Order PI ${ }^{\lambda}$ Controller by Using Response Surface Method for Induction Motor Speed Control, Journal of Control Engineering and Applied Informatics, 18, 2, 20-27, (2016).

[8] Demirtas, M. ve Musa, A., A comparative study of neural networks and fuzzy systems in modeling of a nonlinear dynamic system, An International Journal of Optimization and Control: Theories \& Applications, 1, 1, 65-73, (2011).

[9] Ustun, S.V. ve Demirtas, M., Optimal tuning of PI speed controller coefficients for electric drives using neural network and genetic algorithms, Electrical 
Engineering, 87 , 2, 77-82, (2005).

[10] Demirtas, M., ve Karaoglan, A.D., Optimization of PI parameters for DSP-based permanent magnet brushless motor drive using response surface methodology, Energy Conversion and Management, 56, 104-111, (2012).

[11] Dutta, J.R., Dutta, P.K. ve Banerjee, R., Optimization of culture parameters for extracellular protease production from a newly isolated Pseudomonas sp. using response surface and artificial neural network models, Process Biochemistry, 39, 12, 2193-2198, (2004).

[12] Desai, K.M., Survase, S.A., Saudagar, P.S., Lele, S.S. ve Singhal, R.S., Comparison of artificial neural network (ANN) and response surface methodology (RSM) in fermentation media optimization: case study of fermentative production of scleroglucan, Biochemical Engineering Journal, 41, 3, 266-273, (2008).

[13] Gomes, H.M. ve Awruch, A.M., Comparison of response surface and neural network with other methods for structural reliability analysis, Structural safety/., 26, 1, 49-67, (2004).

[14] Bas, D. ve Boyaci, I.H., Modeling and optimization II: comparison of estimation capabilities of response surface methodology with artificial neural networks in a biochemical reaction, Journal of Food Engineering, 78, 3, 846-854, (2007).

[15] Okay, F.Y. ve Özdemir, S., Kablosuz algılayıcı ağlarda kapsama alanının çok amaçlı evrimsel algoritmalar ile artırılması, Journal of the Faculty of Engineering and Architecture of Gazi University, 30, 2, (2015).

[16] Tezer, T., Yaman, R. ve Yaman, G., Evaluation of approaches used for optimization of stand-alone hybrid renewable energy systems, Renewable and Sustainable Energy Reviews, 73, 840-853, (2017).

[17] Sharafi, M. ve ELMekkawy, T.Y., Multi-objective optimal design of hybrid renewable energy systems using PSO-simulation based approach, Renewable Energy, 68, 67-79, (2014).

[18] Subasi, A., Sahin, B. ve Kaymaz, I., Multi-objective optimization of a honeycomb heat sink using Response Surface Method, International Journal of Heat and Mass Transfer, 101, 295-302, (2016).

[19] Wei, L. ve Yuying, Y., Multi-objective optimization of sheet metal forming process using Pareto-based genetic algorithm, Journal of Materials Processing Technology, vol. 208, 1, 499-506, (2008).

[20] Madavan, N.K., Multiobjective optimization using a Pareto differential evolution approach, Proceedings, Evolutionary Computation, 2, 1145-1150, HonoluluUSA, (2002).

[21] Turan, M.D. ve Altundoğan, H. S., Hidrometalurjik Araştırmalarda Yanıt Yüzey Yöntemlerinin (YYY) Kullanımı, Bilimsel Madencilik Dergisi, 50, 3, 11-23, (2011).

[22] Dutka, M., Ditaranto, M. ve Løvås, T., Application of a central composite design for the study of NOx emission performance of a low NOx burner, Energies, 8, 5, 3606-3627, (2015).

[23] Karakuş, M.O. ve Altın, C., İleri Beslemeli Ağ ile Elman Ağı Kullanılarak Hidroelektrik Santralinin Verimi Hesabı: Hirfanlı Baraj1 Uygulama Örneği, Electronic Letters on Science\&Engineering, 10, 2, 1-14, (2014).

[24] Calgan, H., Demirtas, M. ve Balci, M.E., Capacitive Power and Torque Estimation for Self-Excited Induction Generator with Elman Neural Network, Proceedings, 3th Internetional Conference on Engineering and Natural Science, 878-883, Budapest-Hungary, (2017). 
[25] Sharkawy, A.B., Genetic fuzzy self-tuning PID controllers for antilock braking systems, Engineering Applications of Artificial Intelligence, 23, 7, 1041-1052, (2010).

[26] Chen, X., Pareto tree searching genetic algorithm: Approaching Pareto optimal front by searching Pareto optimal tree, Tech. Report Nk-CS-200, 1-2, (2001).

[27] Moura, P. S. ve de Almeida, A. T., Multi-objective optimization of a mixed renewable system with demand-side management, Renewable \& Sustainable Energy Reviews, 14, 5, 1461-1468, (2010).

[28] Demirtas, M., Ilten, E., Calgan, H., Pareto-Based Multi-objective Optimization for Fractional Order $\mathrm{PI}^{\lambda}$ Speed Control of Induction Motor by Using Elman Neural Network, Arabian Journal for Science and Engineering, https://doi.org/10.1007/s13369-018-3364-2. 